\title{
Teaching research and practice of integrated design experiment in photoelectric courses
}

Bing Lei, Jianhua Shi, Wei Wang, Chengfang Duan, Wenjie Jiang, et al.

Bing Lei, Jianhua Shi, Wei Wang, Chengfang Duan, Wenjie Jiang, Hairong Zhong, "Teaching research and practice of integrated design experiment in photoelectric courses," Proc. SPIE 11143, Fifteenth Conference on Education and Training in Optics and Photonics: ETOP 2019, 111433N (2 July 2019); doi: $10.1117 / 12.2523841$ 


\title{
Teaching Research and Practice of Integrated Design Experiment in Photoelectric courses
}

\author{
Bing Lei*, Jianhua Shi, Wei Wang, Chengfang Duan, Wenjie Jiang and Hairong Zhong \\ College of Advanced Interdisciplinary Studies, National University of Defense Technology, \\ Changsha, Hunan 410073, China
}

\begin{abstract}
The photoelectric courses such as photoelectric technology, optical communication, optoelectronics, and photoelectric detection and signal processing, which own the properties of specialty, integrity and practicability, are usually difficult to grasp well only by classroom teaching. To help undergraduates to understand the photoelectric courses' knowledge and improve their problem solving ability, developing the project-based integrated design experiments is an effective method to inspire the students' interest and improve their innovative practical ability.

Firstly, the main properties of photoelectric courses' integrated design are analyzed, and the basic principles of selecting the proper topics to design some training projects are summarized. A well designed project should be comprehensive, feasible and cost effective, and the project can be separated into several parts with gradually increasing difficulty, which is good for implementing it step by step and inspiring the students' potentials. Secondly, some teaching research and practice of integrated design experiments are implemented based on the photoelectric technology course offered in our university, and four integrated design projects are introduced, which are measuring the rotating speed, direction and stop position of a rotating wheel, designing a laser reconnaissance warning and jamming system, making an analog and digital communication system by utilizing a white light LED and making a photoelectric detection system for blood oxygen saturation. The experimental arrangement and implementing experience are also provided and investigated. Thirdly, some crucial problems discovered in our teaching practice, such as optimizing the design contents and demands of project, helping students' to overcome various difficulties, making teachers become experienced, and evaluating the project design results efficiently and accurately, are also analyzed and discussed to improve and perfect the quality of integrated design experiments. In conclusion, the photoelectric integrated design experiments have been introduced to help undergraduates to master the theoretical knowledge and train their problem solving ability, and our teaching practice experiences have been summarized and provided based on the photoelectric technology course, which can be spread to other photoelectric courses.
\end{abstract}

Keywords: integrated design experiment, project-based training, photoelectric courses, photoelectric technology.

\section{INTRODUCTION}

The photoelectric courses such as photoelectric technology, optical communication, optoelectronics, and photoelectric detection and signal processing, which are offered to investigate the generation, transmission, acquisition, transformation and process methods of photoelectric signals in the real systems, and they usually involve comprehensive applications including multiple theoretical knowledge and engineering techniques. The photoelectric courses own the properties of specialty, integrity and practicability, and they are usually difficult to grasp well only by classroom teaching. Generally speaking, the teaching activities include three levels: theoretical teaching, course experiment and integrated design experiment, and the integrated design experiment is the final and the most important teaching activities in the whole teaching procedures [1,2]. To help undergraduates to understand the photoelectric courses' knowledge and improve their problem solving ability, developing the project-based integrated design experiments is an effective method to inspire the students' interest and improve their innovative practical ability.

In this paper, the basic principles of selecting the project topics to implement the integrated design experiments are analyzed and discussed firstly. Some teaching research and practice of integrated design experiments are implemented based on the photoelectric technology course, and the problems and solutions in the practical teaching process have also been summarized discussed to guide other photoelectric courses.

*leibing_2000@126.com; phone 086 0731-87004103 


\section{SELECTING PROPER PROJECT TOPICS}

According to the properties of photoelectric courses, the guiding ideology of offering integrated design experiments is to help undergraduates to understand the photoelectric courses' theoretical knowledge and improve their problem solving ability, and selecting or designing some appropriate project topics is very important for carrying out the integrated design experiments successfully. Three basic principles for selecting the proper topics to construct some training projects are summarized. The first principle is that the selected project topic should be comprehensive, which means that the project should not only contains the main knowledge points of the curriculum, such as optical source, detector and photoelectric signal processing [3], but also involves employing the professional skills of optics, electronics and mechanics to solve a real practical problems. Training the students' comprehensive designing ability and problem solving ability are the key points of the course. The second principle is that the selected project topic should be feasible and operable, which means that the project owns moderate workload and difficulty and can be accomplished by most students with their great effort. If the project is quite difficult and its workload is huge, the practical training effects will be poor and the students will dislike the comprehensive design experiments. On the contrary, these projects involve several separated parts with gradually increasing difficulty, which is good for carrying out it step by step and inspiring the students' potential. If the project can be separated into several independent parts, some difficult parts needing extra techniques or skills can be prepared well in advance to decrease the students' workload. The third principle is that the selected project topic should be cost effective. Since the integrated design experiments usually offered for all students as comprehensive training steps, a large number of experimental equipment is needed. If the cost of a single set experimental system is expensive, the total cost will be huge and difficult to implement. Actually, some common experimental equipment, such as the signal generator, oscilloscope and power supply, can be shared with other professional experiments, and they can be reused every year and do not increase the running cost. The main running cost of the integrated design experiments is the consumables, which need to be supplied every year.

According to our practical experiences in our university, we have chosen four independent projects as the topics of integrated design experiments in the photoelectric technology course, which are measuring the rotating speed, direction and stop position of a rotating wheel, designing a laser reconnaissance warning and jamming system, making an analog and digital communication system by utilizing a white light LED and making a photoelectric detection system for blood oxygen saturation. The related knowledge points and main combining parts of four selected projects are summarized and shown in Tab.1.

Tab. 1 The related knowledge points and main combining parts of four selected projects

\begin{tabular}{|c|c|c|c|c|c|}
\hline \multirow{2}{*}{$\begin{array}{l}\text { Name of the } \\
\text { project }\end{array}$} & \multirow[b]{2}{*}{ Optical source } & \multirow[b]{2}{*}{ Detector } & \multicolumn{3}{|c|}{ Photoelectric signal transformation and processing } \\
\hline & & & $\begin{array}{c}\text { Optical signal } \\
\text { transformation }\end{array}$ & $\begin{array}{l}\text { Photoelectric signal } \\
\text { transformation }\end{array}$ & $\begin{array}{c}\text { Electrical signal } \\
\text { processing }\end{array}$ \\
\hline $\begin{array}{l}\text { Rotating speed, } \\
\text { direction and } \\
\text { stop position } \\
\text { measurement }\end{array}$ & LED & $\begin{array}{c}\text { Photoelectric } \\
\text { triode, } \\
\text { PIN photoelectric } \\
\text { diode }\end{array}$ & $\begin{array}{l}\text { Mechanical optical } \\
\text { modulation, } \\
\text { Focusing optical } \\
\text { system }\end{array}$ & $\begin{array}{l}\text { Spectrum response } \\
\text { of optical source } \\
\text { and detector }\end{array}$ & $\begin{array}{l}\text { Signal shaping, } \\
\text { Pulse counting, } \\
\text { Phase } \\
\text { discrimination }\end{array}$ \\
\hline $\begin{array}{c}\text { Laser } \\
\text { reconnaissance } \\
\text { warning and } \\
\text { jamming } \\
\text { system } \\
\end{array}$ & $\begin{array}{l}\text { Laser diode } \\
\text { sunlight }\end{array}$ & $\begin{array}{c}\text { PIN photoelectric } \\
\text { diode, } \\
\text { Photosensitive } \\
\text { resistor }\end{array}$ & $\begin{array}{l}\text { Laser collimation, } \\
\text { Optical emitting } \\
\text { system, Pulse coded } \\
\text { modulation }\end{array}$ & $\begin{array}{l}\text { Spectrum response } \\
\text { of optical source } \\
\text { and detector }\end{array}$ & $\begin{array}{l}\text { Signal shaping, } \\
\text { Weak signal } \\
\text { detection, Signal } \\
\text { correlation } \\
\text { processing }\end{array}$ \\
\hline $\begin{array}{l}\text { White light } \\
\text { LED } \\
\text { communication } \\
\text { system }\end{array}$ & White light LED & $\begin{array}{l}\text { PIN photoelectric } \\
\text { diode, BPW34 }\end{array}$ & $\begin{array}{l}\text { Analog and digital } \\
\text { modulation, Optical } \\
\text { emitting system }\end{array}$ & $\begin{array}{l}\text { White light LED } \\
\text { drive emitting, } \\
\text { Demodulated light } \\
\text { signal }\end{array}$ & $\begin{array}{l}\text { Signal amplifying } \\
\text { and shaping, power } \\
\text { amplifying, LED } \\
\text { digital tube display }\end{array}$ \\
\hline $\begin{array}{l}\text { Photoelectric } \\
\text { detection } \\
\text { system for } \\
\text { blood oxygen } \\
\text { saturation }\end{array}$ & $\begin{array}{c}\text { Red LED } \\
\text { Infrared LED }\end{array}$ & $\begin{array}{l}\text { PIN photoelectric } \\
\text { diode, BPW34, } \\
\text { OPT101 }\end{array}$ & $\begin{array}{l}\text { Digital modulation } \\
\text { and optical emitting } \\
\text { system, } \\
\text { Transmission of red } \\
\text { and IR light }\end{array}$ & $\begin{array}{l}\text { Absorption of red } \\
\text { and IR light in } \\
\text { blood oxygen, } \\
\text { Spectrum response } \\
\text { of optical source } \\
\text { and detector }\end{array}$ & $\begin{array}{l}\text { Signal amplifying } \\
\text { and filtering, A/D } \\
\text { transformation, } \\
\text { LED digital tube } \\
\text { display }\end{array}$ \\
\hline
\end{tabular}




\section{TEACHING PRACTICE OF PHOTOELECTRIC TECHNOLOGY INTEGRATED DESIGN}

The teaching practice of integrated design experiments have been implemented based on the photoelectric technology course in the last five years. Since the integrated design experiments have great difference with the traditional classroom teaching, the teaching activities carried out in the laboratory and the main job of teachers is to provide correct guidance and help students solve the problems meet in experiments. The teaching activities should be organized carefully to obtain better effects from the degree of both teachers and students, and the detailed measures and demands are introduced as follows.

From the degree of teachers, in addition to making good preparation for selecting proper project topics, they have to complete the following preparing work. The first thing is to configure the hardware platforms for the experimental systems, the consumables and some difficult parts should be prepared well before the class begins. The second thing is to form a instructing teacher group with different research background, they are good at optics design, electronics design and software programming respectively, and they usually instruct students in the basic steps of selecting the research topic, literature investigation and reading, solution design and provement, theory analysis and simulation, experimental validation, debugging the demonstration system, writing a scientific research report, summarizing the research findings and achievements, and academic exchange etc. [4]. The third thing is to write the experimental lecture contexts, they usually includes the experimental purpose, design contents and demands, design thinking and debug methods, scoring standard etc., which is quite important to help the students to complete their comprehensive design tasks. The forth thing is to divide the students into several research groups, which usually contains 2 or 3 members with different skilled abilities. The research group arrangement is not only good for implementing the design task, but also good for developing their team work spirits. The fifth thing is to work out the scoring standard. For example, the final grade of course contains four parts, the prototype accounts for $60 \%$, the design report accounts for $20 \%$, the presentation accounts for $10 \%$ and the team work spirits accounts for $10 \%$. These groups completed the design task with novel scheme or obtained excellent experimental results can win extra points as bonus.

From the degree of students, they are the principle part and center of the integrated design activity, and most of the design work should be completed by themselves. The most important and time-consuming part of the teaching practice is the design and debug process, which includes the parts of theoretical design, module fabrication and system debugging. A well-organized teaching activity should separate the whole process into several independent parts with gradually increasing difficulty, which is good for implementing the research work efficiently and inspiring the students' potentials.

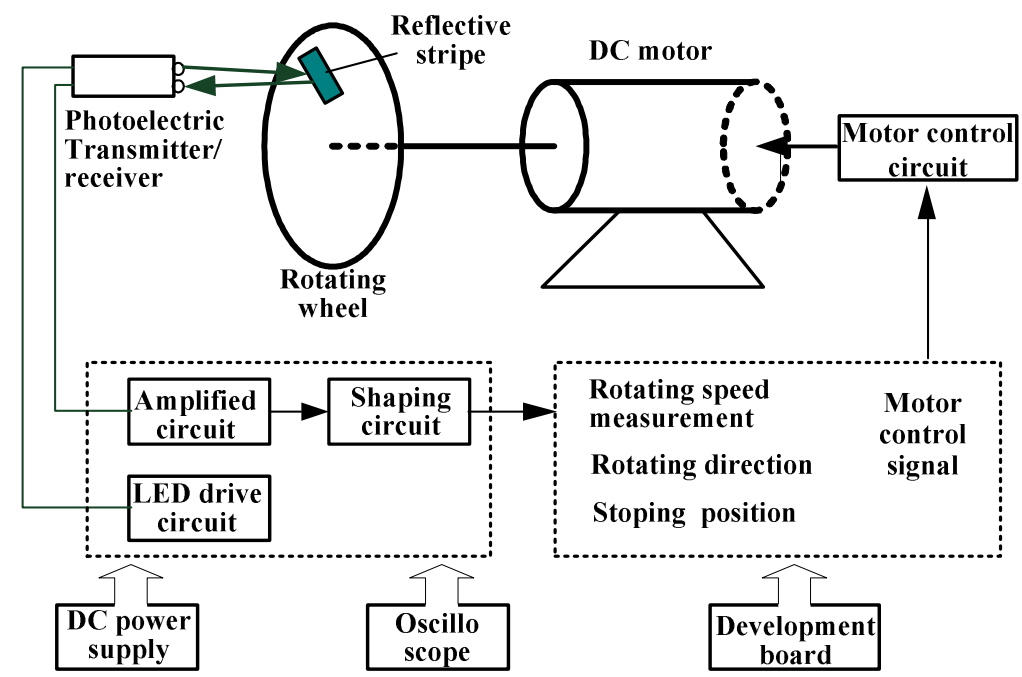

Fig. 1 The block diagram of our designed system of measuring the rotating speed, direction and stop position of a rotating wheel.

The block diagram of our designed system of measuring the rotating speed, direction and stop position of a rotating wheel is shown in Fig. 1, which just indicate a possible demonstration, and the measurement scheme can be various according to different design thinking. Taking the reflective stripe for example, different research group often pastes the 
stripes in different forms, which can show the students' creativity and flexibility adequately. The accomplished prototype system of measuring the rotating speed, direction and stop position of a rotating wheel is shown in Fig. 2.

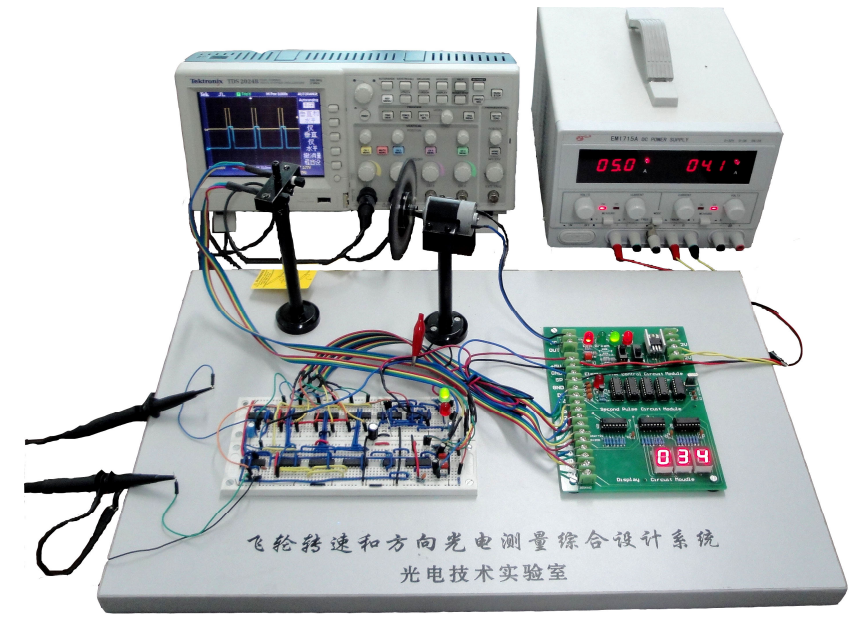

Fig. 2 The prototype system of measuring the rotating speed, direction and stop position of a rotating wheel.

The block diagram of our specially designed laser reconnaissance warning and jamming system is shown in Fig. 3, and the corresponding experimental prototype system is shown in Fig. 4.

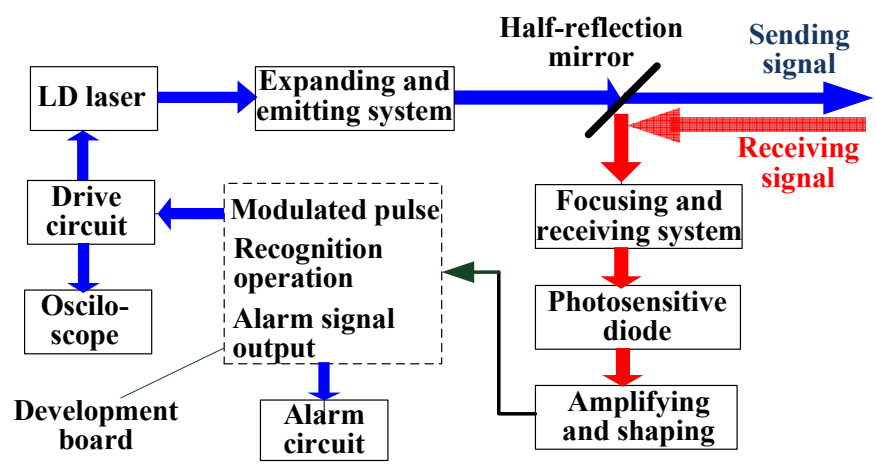

Fig. 3 The block diagram of our designed laser reconnaissance warning and jamming system

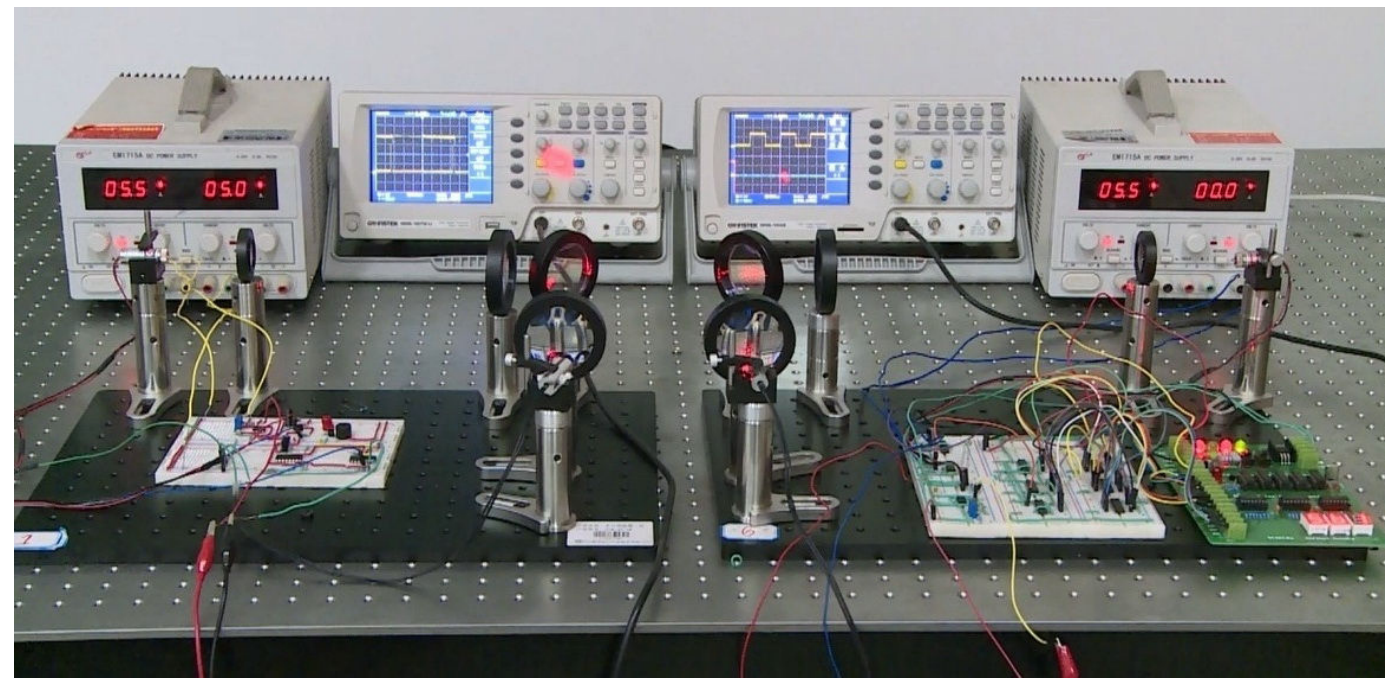

Fig. 4 The prototype system of demonstrating the laser reconnaissance warning and jamming process. 
The block diagrams of optical communication systems by employing the white LED are shown in Fig. 5, and the analog audio signal and digital coding signal are transmitted by the experimental setups shown in Fig. 5(a) and Fig. 5(b). In the digital information transmission experiment, the development board with the STC89C51 chip is utilized to control the digital coding and sending the signal, and the received digital information is demodulated and displayed by the digital tubes in the development board. The maximum communication distance in our experiments is about one meter, and the distance will decrease if the system is not designed and debugged well, and thus it is an important assessment parameter.
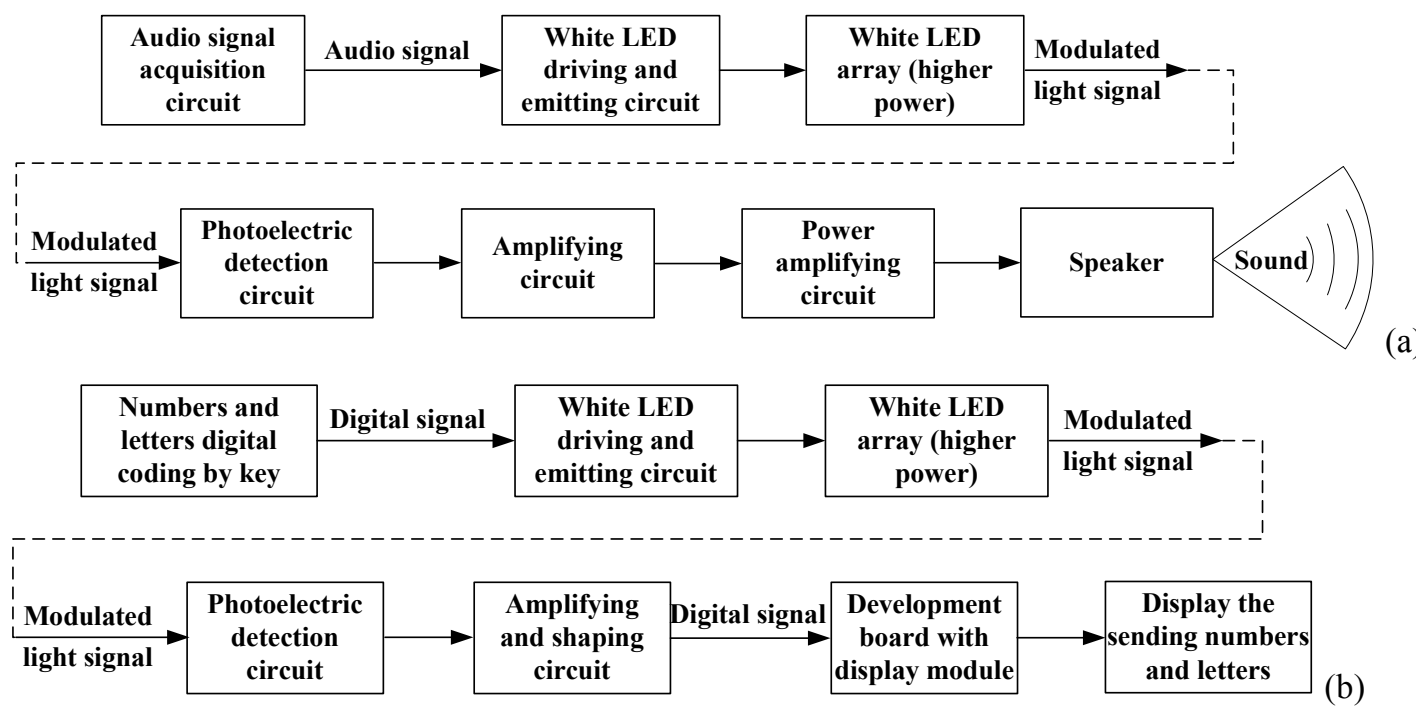

Fig. 5 The block diagram of an analog and digital communication system by utilizing white light LED.

(a) transmitted the analog audio signal, (b) transmitted the digital coding signal.

The block diagram of photoelectric detection system for measuring the blood oxygen saturation is shown in Fig. 6, which indicates the structure composition and basic working principle intuitively. The amplifying and filtering techniques of weak signal is very important in this experiment, which determines whether the blood oxygen signal can be observed or not. The double channel analog to digital transferring acquisition and signal processing in a MCU are also significant for obtaining the correct value of blood oxygen saturation.

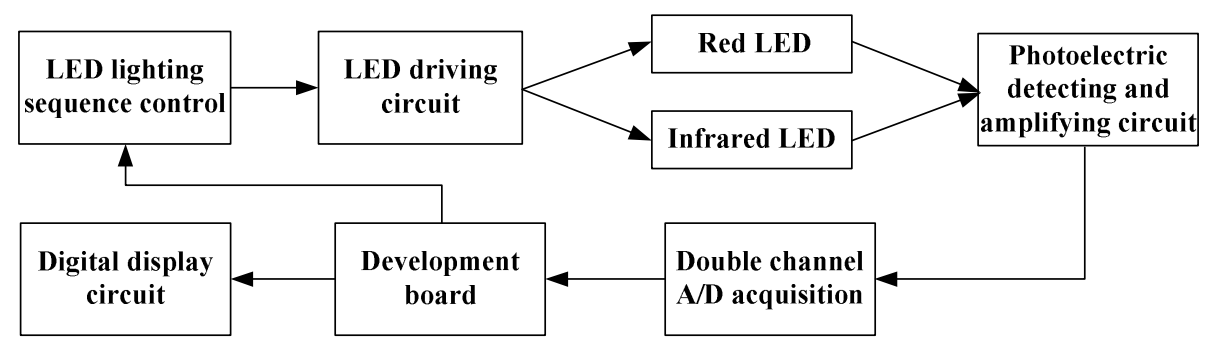

Fig. 6 The block diagram of a photoelectric detection system for blood oxygen saturation.

\section{PROBLEMS AND SOLUTIONS IN TEACHING RESEARCH AND PRACTICE}

The key point comprehensive design experiments are guide students to complete a real work dependently, and training the students to grasp the skills to solve detailed problems. As a matter of fact, both the teachers and students will encounter various problems in the real teaching practice, since the comprehensive design project usually involves the integrated knowledge of optics, electronic science and computer science. Firstly, the students may not know how to design the solution and how to start the job, and the teachers should help them to work out a plan and guide them to separate a complicated problem into several simple problems. Secondly, when the students debug some single modules, such as photoelectric detection circuit, amplifying and filtering circuit, they usually do not know how to examine and analyze the circuit to find out where the fault exist. The teachers should not inform the answers directly, but guiding the 
students to check the textbooks and analyzing the basic working principle of the circuit, and then the problems will be solved naturally and the students will grasp the related knowledge more accurately. Thirdly, in the integrated debugging stage, many strange problems may occur in the system, which are not discovered in the single module testing process. It is a good chance to train students' ability of analyzing and solving problems. The teachers should provide the basic ideas and methods of solving these problems, and teach students to remove the faults one step by step, such as confirming the source of problem is whether optical or electrical, hardware or software. Fourthly, the instruction teacher should possess experienced professional knowledge to solve the stochastic and multiplex problems proposed by students. However, forming the instruction teacher group with different research background is an effective method to solve the problem. Finally, evaluating the experimental results is also a problem, and the biggest puzzle is that different research group provides the same result due to the project topic is identical. In order to solve the problem, the teacher can allocate different design parameters and demands to each research group, and put forward some key questions to check whether the students complete the design task by themselves or not.

\section{CONCLUSION}

The integrated design experiments in photoelectric course have been investigated and practiced in the past five years, and the teaching practice experiences have been summarized and provided based on the photoelectric technology course. In this paper, the main properties and project selecting principles are analyzed and summarized firstly, and four integrated design projects are introduced based on the photoelectric technology course offered in our university, and then some crucial problems discovered in our teaching practice are also analyzed and discussed to improve and perfect the quality of integrated design experiments. In conclusion, the photoelectric integrated design experiments have been proved to be an effective way to help undergraduates to master the theoretical knowledge and train their problem solving ability, and our teaching practice experiences obtained from the photoelectric technology course can be spread to other photoelectric courses.

\section{Acknowledgments}

This work is supported by the education and teaching research project of Education Department of Hunan Province and the education, teaching reform research undergraduate project of National University of Defense Technology and the "Industry and university cooperative education" project of Ministry of Education of China.

\section{REFERENCES}

[1] W. J. Jiang, W. K. Xie, J. H. Shi, H. T. Ma, "The study and practice of opto-electronic integrated design curriculum's teaching," Journal of Higher Education Research, 37(2), 105-109 (2014).

[2] J. H. Shi, H. T. Ma, W. J. Jiang, B. Lei, W. K. Xie, "A research on 'theory-practice-innovation' trinity network course," Journal of Higher Education Research, 37(4), 84-88 (2014).

[3] W. J. Jiang, J. H. Shi, W. K. Xie, H. T. Ma, X. W. Zeng, "Photoelectric technology (second edition)," Science Press, 2014.

[4] B. Lei, Y. Feng, W. Liu, J. H. Shi, H. J. Hu, "Exploration on cultivating mode of talents with innovation practical ability based on SITP," Research in Teaching 38(6), 97-101 (2015). 